\title{
RANCANG BANGUN SISTEM MONITORING RADIASI BERBASIS WEBSITE
}

\author{
Djiwn Harsono ${ }^{1}$, Adi Abimanyu ${ }^{2}$, Juli Yandika ${ }^{3}$ \\ 1) STTN, BATAN, Yogyakarta, Indonesia, djiwo@batan.go.id \\ 2) PSTA, BATAN, Yogyakarta, Indonesia, email \\ 3) STTN, BATAN, Yogyakarta, Indonesia, email
}

\begin{abstract}
ABSTRAK
RANCANG BANGUN SISTEM MONITORING RADIASI BERBASIS WEBSITE. Sistem monitoring radiasi sangat pentung dalam suatu fásilitas nuklir, karena melalui kegratan monitoring radiasi maka porensi bahaya radiasi dapat dikontrol dan dikurangi. Sistem monitoring radiasi jarak jauh merupakan Salah satu eara untuk meminimalkan resiko potensi bahaya tadiasi, dengan cara berada jauh dari sumber radiasi dan tetap bisa melakukan monitoring sumber radiasi tersebut. Selama kegiatan monitoring, data monitoring radiasi merupakan hal yang penting untuk diketahui secara cepat dan dapat diakses dimanapun. Penelitian ini bertujuan mengembangkan perangkat lunak sistem monitoring radiasi derngan penampil LabVIEW menggunakan state machine jenis arsitektur Queue State Machine, dan membuat database menggumakan XAMPP yang hasilnya dapat dinkses melalui wehsite dejgun waktu komputasi pemrogtaman yang optimum. Hasil pengujian menurjukkan bahwa, sistem telah berlkasil menampilkat data monitoring radiast pada LabVIEW dan membuat database menggunakan XAMPP yang hasilnya dapat diakses melalu website. Data laju paparan yang dikirimkan menggunakan SMS melalui Modem Wavecom dari Alat Monitoring Radiasi, dapat ditampilkan pada LabVIEW dengan waktu komputasi minimal $1053 \mathrm{~ms}$ jika tidak ada delay SMS.
\end{abstract}

Kata kuner monitoring radiasi, modem, SMS. LabVIEW. datubase, wehsite

\section{ABSTRACT}

DESIGN RADIATION MONITORING SYSTEM BASED WEBSITE. Radiation momitoring Sistem is very important in a nuclear facilin, because vadiation monitoring activities can be controlled and reduce the potential radiation hazard Long range fadiation monitoring Sistem is one way to minimise the risk of potential radiation hatards. by being awa from the source of radiation and stilt be ahle to monilite the radiation sowre. During montoring, radiation monitaring datu is important to know quickly and can be access anyshere. This research aims to develop a radiation montzoring System soffuare with LabliEW using state machine archilecture type Queve State Machine, and create a database ksing XAMPP which resuits ean be actess in website. with the optimum conunting time progrant. The results show that, the Syctom has managed to show the radiation monitoring data in LabVIEW and create a database usyng XAMPP which results can be acoess in website. Exposure fate data that is sent using SMS via Modem Wavecom from Radiation Monitoring device, can be displaved on LabVTEW with minimal computational time In53 ms if no deloy SMS.

Keywords: radiation manitoring, modem, SMS, LuhVIEW, datubase, wehsile

\section{PENDAHULUAN}

Radiasi pengion adalah radiasi elektromagnetik atau partikel yang mampu menghasilkan ion-ion sepanjang lintasan di da)am bahan (misalnya sinar-a. sinar- $\beta$, sinar- $\gamma$.
sinar-X, dan neuiron) karena terjadi proses ionisasi ini maka pada materi yang dilalui radiasi akan terbentuk pasangan ion positif dan 
negatif [i]. Radiasi pengion memiliki potensi habaya yang lebih besar dari pada jenis radiasi lainnya, klususnya sinar- $X$ dan gamma. Mengingat potensi bahaya radrasi pengion yang besar thaka perlu dilakukan monitoring radiasi.

Pada umumnya pengukuran laju paparan untuk monitoring radiasi dilakukarı dengan cara pekerja radiasi mendekati sumber radiasi yang dideteksi bersama alat. Hal in memiliki polensi bahaya radiasi semakin besar jika intensilas radiasi yang dideteksi semakin besir. Sistem monitoring radiasi jarak jauh merupakan salati satu cara uniuk meminimalkan resiko tersebut, dengan cara berada jauh dari sumbet radiasi dan tetap bisa melakukan monitoring sumber radiasi tersebut, Penelilian sistem monitoring radiasi jarak jauh telah dibuat oleh Ridho Fazunta A, pada tahun 2013 dengan judul penelitian "Komputerisasi Monitoring Radiasi Melalui SMS".

Mengingat perkembangan zaman akhir decade ini bahwa sebagian besar informasi bisa didapatkan melalui internet, maka pénelitian Ridho Fazunta A dikembangkan ke arah tersebut Penelitian "Rancangbangun Sistem Monitoring Radiasi Berbasis Website" merupakan pengembangan penelitian Ridho Fazunta A yang bertujuan mengernbangkan perangkat lunak sistem monitoring radasi dengan penarmpil LabVIEW menggunakan state machine jenis arsitektur Quezt State Machine, dan membuat database menggunakan XAMPP yang hasilnya dapat diakses melalui website dengan wakau komputasi pemrograman yang optimum,

Pengembangan ini bermanfaat untuk meningkatkan nilai ergonomi suatu perusabaan dalam melakukan monitoring radiasi. Perangkat lunak sistem monitoring radiasi ini akan dapat dipantau melalui PC atamá dengan program penampil LabVIEW. Pada PC utama senver ini juga akan mengolah log book dari hasil monitoring dengan membuat database menggunakan program MySQL. Selain itu, untuk mempermudah monitoring maka hasilnya juga dapat diakses secara online melalai $w e b$. Demi mendukung pelaksanaan keamanan selama monitoring, maka pada penampil LabVIEW di PC utama dan web akan ditambahkan sistem alarm saat paparan melebihi batas aman. Selain in, System ini juga dapat mempermudah proses dokumentasi dari kegiatan monitormg radiasi.

\section{TEORI \\ Website}

Wsbsite merupakan sejumlah halaman webyang memiliki lopik saling terkait. terkadang disertai pula dengan berkas-herkas gambar, video atau jenis-jenis berkas lainnya. Sebuah silus $w e b$ biasanya ditempatkan setrdaknya pada sebuah server web yang dapat diakses melalui jaringan internet alau jaringan lokal Lacal Area Netnork (LAN) melalui alamat internet yang dikenali sebagai URL. Gabungan atas semua sims yang dapat diakses publik di internet disebur pula sebagai World Wide Web atau iebih dikenal dengan singkatan WWW ${ }^{12}$.

\section{HTML, CSS, dan PHP}

Hypertext Markup Langiage (HTML) adalah bahasa markup yang umum digunakan untuk membuat halaman web. Apahila di tinjau dari namanya, HTML merupakan bahasa markup atau penandaan terhadap sebuah dokumen teks. Tanda tersebut digunakan ustuk menentukan format atau style dari teks yang ditandai $^{\text {Bi? }}$.

Gascading Style sheet (CSS) adalah salah satu bahasa pemrograman weh yang digunakan untuk mempercantik halaman web dan mengendalikan beberapa komponen dalam sebuah web sehingga akan lebih terstruktur dan seragam. CSS dapat kata gunakan dalam mengendalikan ukuran gambar, wartia teks, warna tabel, ukuran border, warna border, warna byperlink, warna mouse over, spasi antar paragraf, spasi antar teks, margin kiri, kanan atas, bawah. dan parameter lannya ${ }^{\text {It }}$,

PHP merupakan singkatan dari llypertext Preprocessor yang digunakan sebagai bahasa seript server side dalam pengembangan weh yang disisipkan pada dokumen HTML. Berbeda dengan HTML yang hanya bisa menampilkan konten statis. PHP bisa berinteraksi dengan databose, file dan folder, sehingga membuat PHP bisa menampilkan konten yang dinamis dar sebush website ${ }^{74}$ ?

\section{XAMPP}

XAMPP adalah perangkat lunak open source berisi kompilasi dari beberapa program yang mendukutig banyaksistem operisi. XAMPP berfmgsi sebagai scrver yang berdiri sendiri (localhost) dan terdiri atas program 
Apache HTTP Server. MySQL database, dan penerjemah bahasa yang ditulis dengan bahasa pemrograman PHP dan Perl. Nama XAMPP merupakan singkatan dari $\mathrm{X}$ (program ini dapat dijalankan dibanyak sistem operasi, seperti Windows, Linux, Mac OS, dan juga Solaris), Apache, MySQL, PHP dan Perl ${ }^{|5|}$.

\section{Database}

Database merupakan kumpulan data yang terintegrasi dan diatur scdemikian rupa sehingga data tersebut dapat dimanipulasi, diambil dan dicari secata cepat ${ }^{[5]}$. Database berbeda dengan Darabase Management Sistem. Untuk mengelola database diperltakan suatu perangkit lunak yang disebut DBMS (Database Management System). DBMS merupakan suatu sistem perangkat lunak yang memungkinkan user (pengguna) untuk membuat, memelihara, mengontrol, dan mengakses database secara praktis dan etísien. Dengan DBMS, user akan lebih mudah mengontrol dan memanipulasi data yang ada ${ }^{\text {厂j }}$. Beberapa contoh program DBMS yaitu. Microsoft SQL Server. Oracle, Sybase, dBase, Microsoft Access, MySQL dari Sun MicroSystems (Oracle), DB2 dari IBM dan lain-lain ${ }^{7]}$

\section{MySQL}

MySQL merupakan salah satu contoh so/tware dari DBMS. MySQL ${ }^{\mid 5 T}$ menganut atau mengimplementasikan model database relasional maka MySQL terkadang disebut sebagai Relasional Database Management System (RDBMS). MySQL merupakan software RDBMS (atau server database) yang dapat mengelola database dengan sangat cepat, dapat menampung data dalam jumlah sangat besar, dapat diakses oleh banyak user (multiuser) dan dapat melakukan suatu proses secara sinkron atau berbarengan (multi-threaded).

\section{SQL}

SQL merupakan bahasa atau kumpulan perintah standar yang digunakan untuk berkomunikasi dengan datahase. Bahasa SQL yang digunakan tidak selalu sama Antara database satu dengan database lain, tergantung fitut-litur yang didukung oleh darabase tersebut. Penulisan perintah dalam Bahasa SQL adalah incasesensitive, artinya perintah 'create database test' sama dengan perintah 'CREATe
Datahase rest'. tetapi tidak sama dengan 'create dhase Test' (nama database nya berbeda) $[7]$.

\section{PERANCANGAN DAN PEMBUATAN}

Mustrasi alat dan Biok diagram sistem dapat dilihat pada Error! Reference source not found. dan Error! Reference source not found.

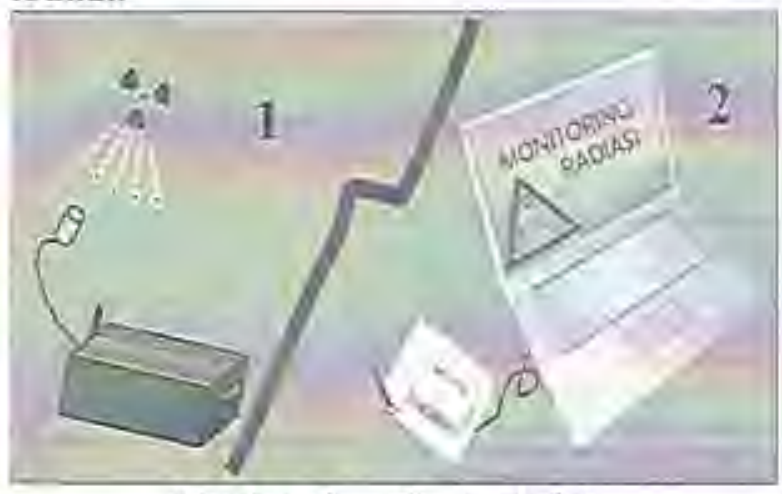

Gambar. 1. Ilustrasi alat

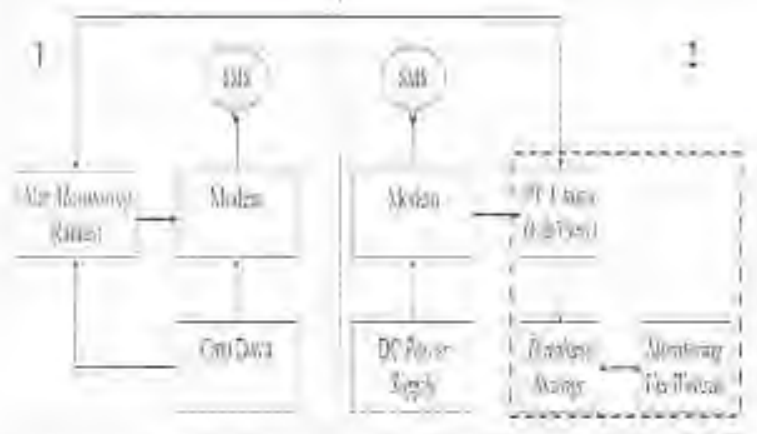

Gambar, 2. Blok diagram monitoring radiasi melalui SMS berbasis website

pada bagian 1, alat yang digunakan untuk penelitian terdiri dari dua yaitu, alat monitoring radiasi dan modem. Alat monitoring radiasi dan modem akan mendapatkan supply daya dari catu daya. Alat monitoring ini akan mengakusisi laju paparan radiasi dan memproses data tersebut merjadi data yang siap dikirimkan ke semer melahui SMS serta mengirimkannya menggunakan modem. Oleh server data tersebut kemudian diproses untuk ditampilkan pada website.

Error! Reference source not found. merupakan blok diagram secara keseluruhan dari alat dan software. Penelitian ini difokuskan pada pembuatan aplikasi penampil menggunakan LabVIEW sebagai GUI dan menginputkan data ke MySQL sehingga menjadi datahase yang memungkinkan untuk 
diakses melalui wobsite. Selain mengakses datahase. pada website juga mampu melakukan monitoring radiasi secara realtime.

\section{Data Flow Diagram}

Data-data yang dapat terlihat di website merupakan data olahan yang telah didapat dari berbagai sumber. Berikut ini rencana sumber dan tujuan data:

1. Aplikasi LabVIEW Monitoring Radiasi akan memberikan data waktu, langgal dan keterangan kepada sistem.

2. Alat Monitoring Radiasi akan memberikan data laju paparan radiasi kepada sistem.
3. Operator akan memberikan data nama operator dan lokasi kepada sistem.

4. Sistem akan memberikan data laju paparan kepada Aplikasi LabVIEW Monitoring Radiasi.

5. Sistem akan memberikan data monitoring realtime dan arsip data monitoring kepada website, operator dan supervisior.

Berdasarkan 5 rencana tersebut maka dapat dibuat sebuah Data Flow Context Diagram seperti pada Error! Reference source not found.

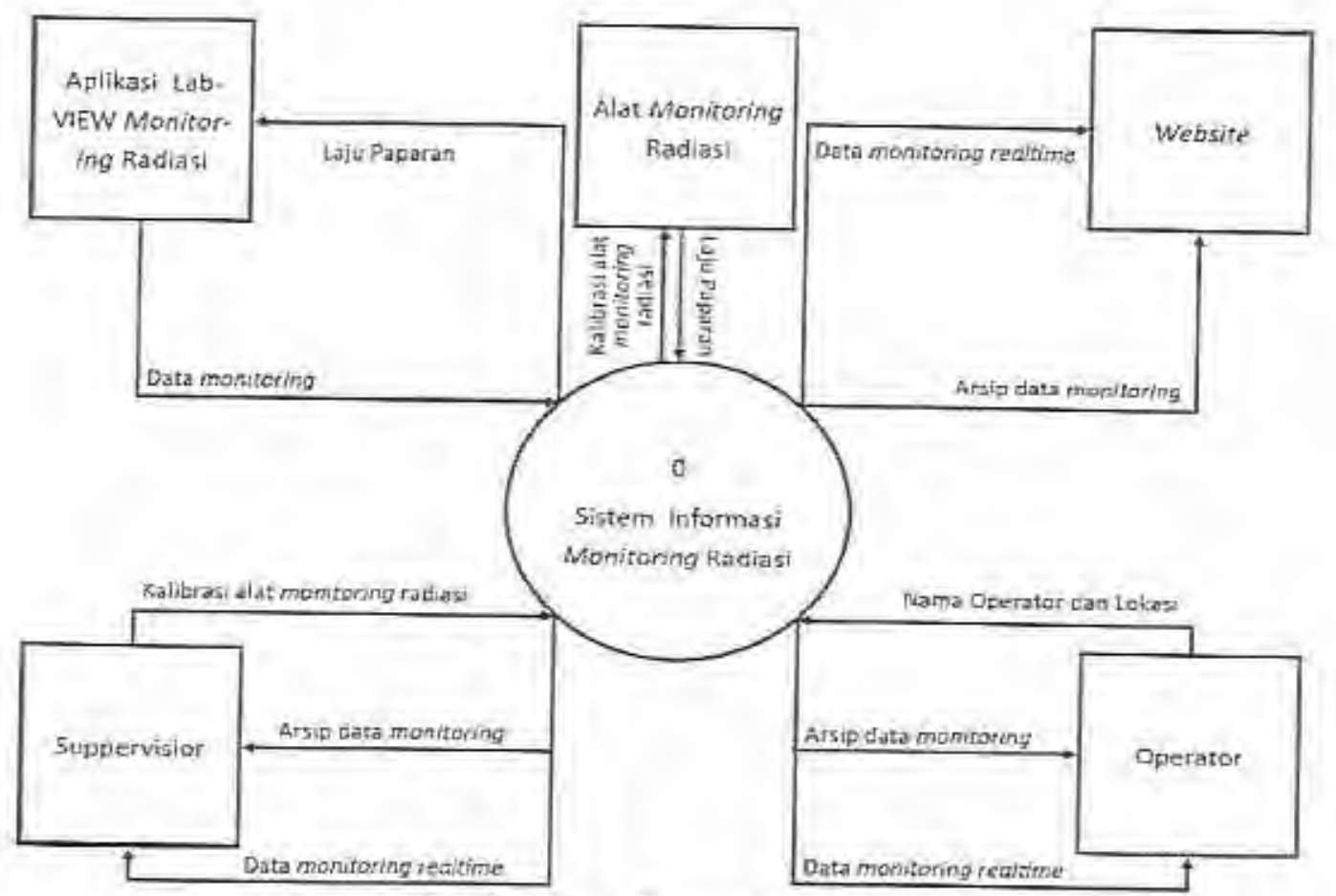

Gambar. 3. Context Diagram

Gambat 3 merupakan data flow context diagram, diagram level tertinggi ini menggambarkan hubungan sistem dengan lingkungan luarnya. Nama sistemnya adalah Sistem Informasi Monitoring Radiasi. Terdapat lima terminator dalam sistem ini yaitu, aplikasi LabVIEW monitoring radiasi, alat monitoring radiasi, website, supervisor dan operator.

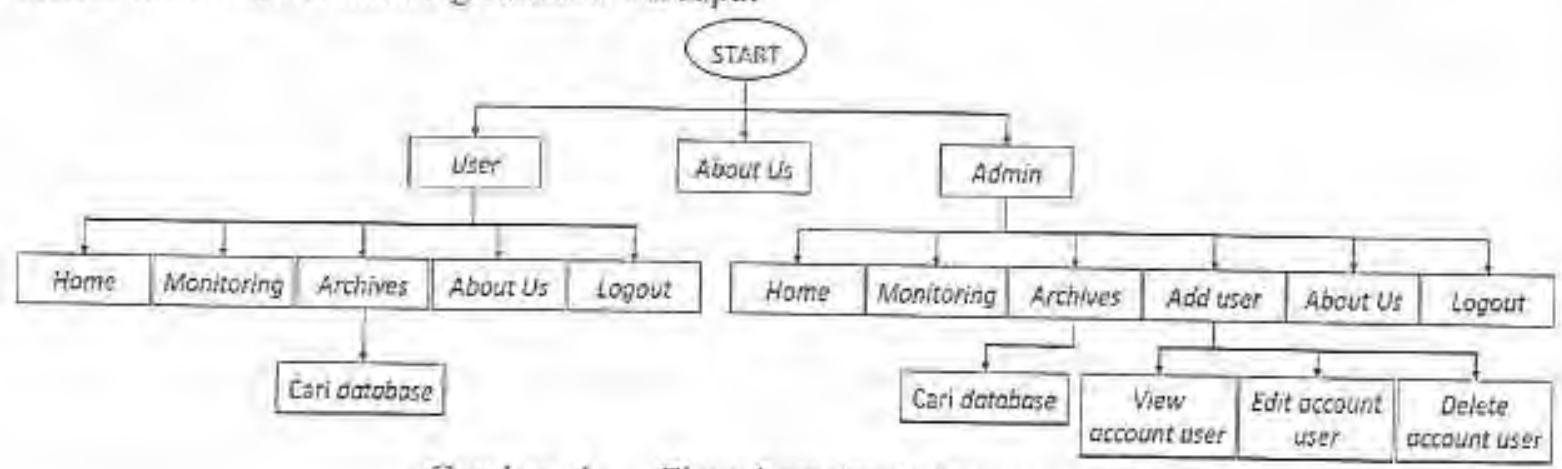

Gambar, 4. Flowschart desain halaman web 


\section{Program Penampil Website}

Pada flowchart Gambar 4 setelah pengguna login dan mulai masuk ke halaman utania, maka pada halaman berikutnya akan tampil lima buah menu utama yang dapat dipilih oleh perigguna.

Pembuatan program penampil website ini akan menggunakan seftware Notepad-. Semua file program yang dibuat akan disimpan menjadi satu folder khusus dan diletakkan dalam folder htdocs pada folder instalasi XAMPP. Ada tiga tipe file yang dibuat untuk progran penampil wetsitte im, yaitu file HTML, file CSS dan file PHP. Selain tiga tipe File ini, terdapat juga satu folder khusus yang di dalamnya lerdapat semua file gambar yang akan ditampilkan pada website.

\section{Database}

Pada penelitian ini ada tiga tabel dalabase yang dibuat, yaitu tabel database login web. monitoring radiasi, dan tanggal kalibrasi pada aplikasi LabVIEW. Tabel databuse akan dibuat melálui aplikasi MySQL yang tclah tertanam pada aplikasi XAMPP dengan menggunakan bahasa SQL, sêperti yang dijelaskan pada dasar teori.

Tabel datahase login web berisi lima kolom yajiu, id, username. hakakses, password1, dan password2. Tabel database ini berfungsi untuk login masuk ke halaman tuama pada website, Tabel dalabase ini dibual dengan nama "admin'. Kolom "id" berfungsi untuk nomor urut account Kolom "username" berfungsi sebagai nama pengguna website. Kolom "hakakses" berfungsi sebagai acuan siapa yang sedang login ke wehsite. Kolom passwordl merupakan password account yang relah diubah fungsi menjadi mo5. Kolom password2 merupakan password account asli.

Tabel database berikutnya adalah tabel data monitoring, tabel ini diberi nama montoring", Tabel monitoring terdin dari tujuh kolom vaitu, kolom id, operator, lokasi. tanggal, waktu, laju dan keterangan. Data pada darahase label monitoring berasal dari aplikasi LabVIEW monitoring radiasi. Kolom id berisi nomor urutan data monitoring. Kolom operator berisi nama operator yang bertanggung jawab saat melakukan monitoring Kolom lokasi berisi lokasi tempat peneacahan sumber radioaktif Kolom tanggal berisi tanggal saut melakukan monjtoring. Kolom waktu berisi waktu saat pengambilan sctial dáta laju paparan. Kolom laju berisi data laju paparan radiasi. Kolom keterangan berisi keterangan data aman atau bahaya, nilai dari laju paparan tersebut.

Tabel database ketiga adalah tabel yang berisi data tanggal kalibrasi terakhir yang dilakukan pada program aplikasi LabVIEW. Tabel datahuse tersebut diberi nama tanggalkalibrasi?. Tabel tanggalkalibrasi ini terdiri dari dua kolom yaitu. ID, dan Tanggalkal. Kolom ID berfungsi sebagai nomor urut data dari tanggal kalibrasi yang telab dilakukan. Kolom Tanggalkal berfungsi sebagai data dari tanggal kalibrasi yang telah dilakukan.

\section{HASIL DAN PEMBAHASAN Waiktu Komputasi Program LabVIEW}

Pengujian waktu komputasi program LabVIEW bertujuan untuk mengetahui berapa waktu yang dibutulikan untuk pemrosesan data schingga bisa tertampil secara continue. Pengujian ini akan menggunakan SMS via handphone sebagai simulasi pengganti data dari alat monitoting radiasi, Modem Wavecom sebagai receiver data, dan laptop dengan aplikasi LabVIEW sebagai penampil data. Penggunaar SMS va handphone sebagai simulasi pengganti data laju paparan sumber radiasi darî alat montitoring radiasi, dilakukan dengan alasan keselamatăn agar tidak menimbulkan potensi rerpapar radiasi yang cukup besar.

Setelah data dikirinikan melalui handphone maka data akan diterima oleb modem yang telah terkoneksi dengan laptop. Kemudian data akan dibaca oleh aplikasi LabVIEW untuk diproses hingga dilampilkan. Perighiturigan wakto komputasi dilakukan pada aplikasi LabVIEW menggunakan VI Tick Count (ms), kemudian menghitung selisih waktu pada blok proses terkahir Tick Count dengan blok proses pertama Tick Count. Pengujian waktu komputasi ini akan dilakukan derrgan menguji sub proses respon modem. cari SMS, baca SMS, dan akan dilanjutkan dengan proses terima dátá bingga data tertampil pada tabel.

Pengujian waktu komputasi program LabVIEW bertujnan untuk mengetahui berapa 
waktu minimal yang dibutuhkan program untuk membaca seluruh data SMS yang dikirimkan. Pengujian dilakukan dengan menghitung selisih waktu pada saat pengiriman perintah baca SMS ke modem hingga seluruh data SMS terbaca oleh program, dengan mernvariasikan delay time. Pada pengujian ini handphone akan mengirim satu Jembar SMS alau sama dengan 160 karakler. Setelah itu. program akan membaca format SMS yang dikirimkan modem. Normalnya, format yang diterima program adalah

"AT-CMGR-(indeksS.MS) $<\operatorname{chr}(13)>-C M G R$ $:<\operatorname{chr}(32)>" R E C<\operatorname{chr}(32)>U N R E A D^{\prime \prime}, "(N o m$ orhandphone)"," (tanggal), (waktui)" $<C R><L F$ $>$ (isipesan $)<\operatorname{chr}(13)>O K^{\prime \prime}$ atau sama dengan 232 karakter.

Mengingat format data yang diterima cukup panjang, maka dibutuhkan delay time yang cukup untuk membaca semua format SMS tersebut agar semua data informasi dapat terbaca tanpa ada bagian dari format yang hilang.

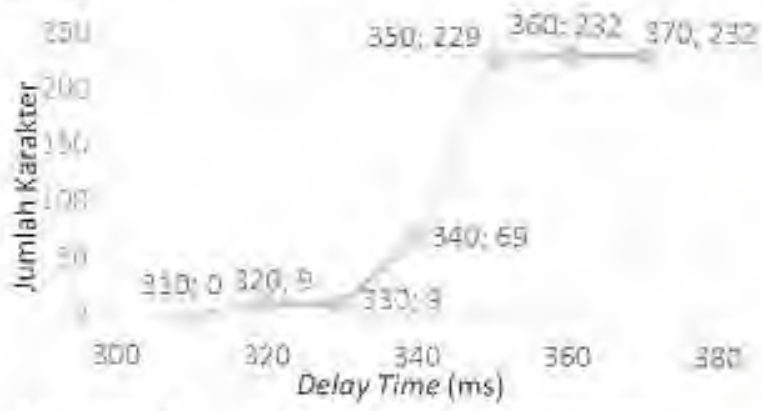

Gambar, 5. Hubungan delay time dengan jumlah karakter

Gambar 5, ditunjukkan hasil pengujian waktu komputasi baca SMS yaitu Jumlah Karakter vs. Delay Time (ms) yang dilakukan 6 variasi delay time y mulai dari $320 \mathrm{~ms}$ sampai dengan $370 \mathrm{~ms}$, dengan interval kenaikan 10 ms. Pada delay time $350 \mathrm{~ms}$ isi SMS yang diterima telah lengkap, tetapi tidak mendapatkan semua format SMS yang diterima. Karena yang dibutuhkan hanya isi SMS saja, maka digunakan delay time $350 \mathrm{~ms}$. dengan pertimbangan efisiensi waktu komputasi program.

Berdasarkan pengujian yang telah dilakukan, didapatkan bahwa waktu komputasi untuk baca SMS hingga data tertampil di tabel LabVIEW adalah $1050 \mathrm{~ms}$. Jadi. akumulasi waktu pemrosesan program dari sast program menerima notifikasi SMS masuk hingga data tampil ke tabel adalah jumlah waktu komputasi cari indeks SMS ditambah waktu komputasi baca SMS. Sehingga akumulasi nya adalah 3 $\mathrm{ms}+1050 \mathrm{~ms}-1053$ ms. Berdasarkan perhitungan tersebut dapat disimpulkan bahwa waktu komputasi program LabVIEW untuk menampilkan data minimal $1053 \mathrm{~ms}$.

\section{Sistem Kescluruhan}

Pengujian sistem keseluruhan akan dilakukan dengan menggunakan alat yang telah dibuat oleh Ridho Fazunta A dengan tambahan surveymeter analog, sumber radioaktif, serta laptop yang telah terinstalasi aplikasi LabVIEW. XAMPP, dan Google Chrome.
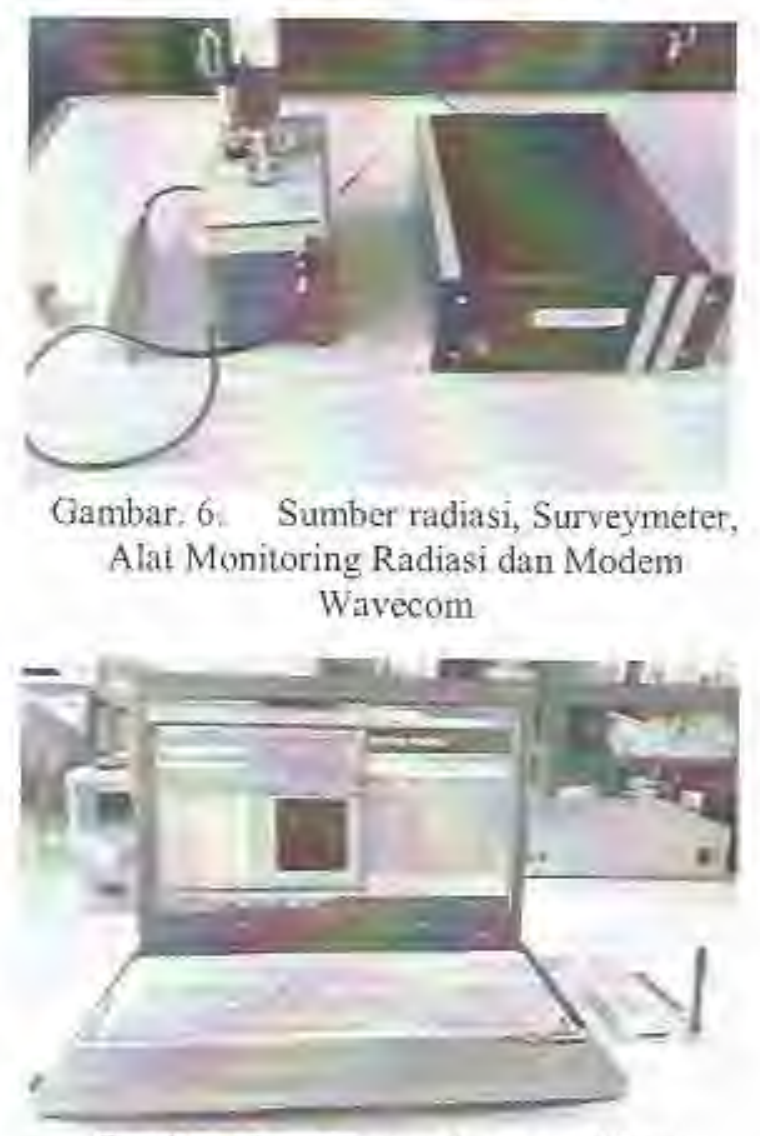

Gambar. 7. Laptop dengan aplikasi penampil data dan Modem Wavecom

Pada Gambar 6 merupakan satu paket alat monitoring sumber radiasi. Pada pengujian sistem keseluruhan ini menggunakan sumber radiasi $\mathrm{Co}-60$ dengan aktifitas $20.81 \mu \mathrm{Ci}$ pada tanggal 1 Agustus 2006. dengan jarak $4 \mathrm{~cm}$ antara sumber radiasi Co-60 dan detektor. Alat Monitoring Radiasi ini akan mencacah laju paparan radiasi, dan akan mengirimkan data tersebut menggunakan SMS melalui modem 
yang terhubung dengan alat ke modem yang terhubung laptop.

Gambar 7 merupakan sistem penampil LabVIEW dan Website pada laptop. Data laju paparan yang tertampil merupakà data laju paparan yang dikirim oleh Alat Monitoring Radiasi. Pada program penampil LabVIEW data laju paparan akan tertampil di tabel dan akan ter-update jika ada data yang masuk, dengan selang waktu selama 30 detik. Selang waktu 30 detik tersebut merupakan default pengaturan dari Alat Monitoring Radiasi. Progrann penampil wetsite akan meng-update data yang masuk setiap 50 detik. Berdasarkan Gambar 6, dan Gambar 7 dapat disimpulkan bahwa sistem telah dapat mencacah sumber radiasi, mengirimkan data menggunakan SMS melalui modem. menampilkannya pada LabVIEW, menyimpan di datahase, dan menampilkannya pada websile.

\section{KESIMPULAN}

Berdasarkan perancangan. pembuatan. percobaan dan analisis yang telah dilakukan, maka dapat disimpulkan bahwa, telah berhasil dirancangbangun perangkat lunak sistem monitoring radiasi dengan penampil LabVIEW dan membuat database menggunakan XAMPP yang hasilnya dapat diakses melalui rebsite. Data laju paparan yang dikirimkan menggunakan SMS melalui Modem Wavecom dari Alat Monitoring Radiast. tapat ditampilkan pada LabVIEW dengan waktu komputasi minimal 1053 ms jika tidak ada delay SMS.

\section{Saran}

Berdasarkan penelitian yang telah dilakukatn, ada beberapa saran yang dapai diberikan yaitu:

1. Komunikasi pengiriman data dapat dikembangkan menggunakan wifi jika alat hanya dioperasikan pada sasu atea saja.

2. Data interupsi serial kalibrasi alat dapai dilakukan via SMS menggunakan modem.

3. Sistem ini dapat dikembangkan menjadi sistem pemetaan laju paparan radiasi berbasis web dengan menambahkan GPS.

\section{DAFTAR PUSTAKA}

1. R. F. Aryapandu, D, Harsono dan A. Abimanyu, "Komputerisasi Monitoring
Radiasi Melalui SMS," STTN- BATAN, Yogyakarta, (2013).

2. A. Hadisaputra, HTML \& CSS Fundamental dari Akar Menuju Daun. Bogor: Cyber Business School, 2012.

3. MAster.com, Menguasai PHP dan MySQL, Jakarta: Kuncikom, (2012).

4. B. Riharjo, Belajar Otodidak Membuat Database Menggunakan MySQL, Bandung: Informatika, (2011),

5. A. Solichin. Pemrograman Weh dengan PHP dan MySQL, Jakarta: Universitas Budi Luhut, (2009).

6. H.P.Halvorsen.Datahase Communication in LabVIEW, Norway: Telemark University College, (2011).

7. M. Akadi, Dasar - Dasar Proteksi Radiasi. Jakarta: PT Rineka Cipta, (2000). 